\title{
Recent Advances in Drug Delivery Systems
}

\author{
Nuno Martinho ${ }^{1}$, Christiane Damgé ${ }^{2}$, Catarina Pinto Reis ${ }^{1 *}$ \\ ${ }^{1}$ CBIOS - Laboratory of Nanoscience and Biomedical Nanotechnology, Faculty of Sciences and Health Technologies (FCTS), Lu- \\ sophone University of Humanities and Technologies (ULHT), Lisbon, Portugal; ${ }^{2}$ Institute of Physiology, Faculty of Medicine, \\ University of Strasbourg, Strasbourg, France. \\ E-mail: ${ }^{*}$ catarinapintoreis@gmail.com
}

Received October $3^{\text {rd }}, 2011$; revised November $12^{\text {th }}, 2011$; accepted November $20^{\text {th }}, 2011$

\begin{abstract}
Drug targeting to specific organs and tissues has become one of the critical endeavors of the century since the use of free drugs in conventional dosage forms generally involves difficulties in achieving the target site at the appropriate dose after or during a proper time period. Consequently, the search for new drug delivery approaches and new modes of action represent one of the frontier research areas. New drug delivery systems include lipidic, proteic and polymeric technologies to provide new sustained drug delivery with better body distribution, drug protection from the harsh external environment and avoidance of drug clearance. Many of these technologies have reached the market therefore proving the benefits of these new carriers. This review covers the generalities of those new carriers and their new advances in drug delivery.
\end{abstract}

Keywords: Nanomedicine, Nanoparticles, Liposomes, Cyclodextrins, Dendrimers, ADEPT

\section{Introduction}

Drug targeting to specific organs and tissues has become one of the critical endeavors of the new century. The search for new drug delivery approaches and new modes of action represent one of the frontier areas which involves a multidisciplinary scientific approach to provide major advances in improving therapeutic index and bioavailability at site specific-delivery [1-4]. The hard to target tissues such as blood-brain barrier permeation limitation can now be overcome allowing the use of therapies otherwise excluded by conventional dosage forms [5]. These new systems can hinder solubility problems, protect the drug from the external environment such as photodegradation and $\mathrm{pH}$ changes, while reducing dose dumping by controlling the release profile $[3,4]$. Moreover, controlled targeting at the site of action and reduced time of exposure at non-targeting tissues increases the efficacy of treatments and reduce toxicity and side effects [6] thus improving patient compliance and convenience.

Biocompatibility is one of the major pre-requisites for pharmaceutical use, and designing a formulation to fit the physicochemical properties of the drug poses the challenge to new dosage forms. Nowadays, the versatility and biodegradability of polymers such as poly(D-L-lac- tide-co-glycolide) (PLGA) constitute a leading approach to new dosage forms to avoid physiological and pathological hurdles encountered in developing targeting strategies. This approach can improve the pharmacokinetic profiles of numerous drugs through the delivery of a higher dose at the site-specific organs by using ligands [7] while conferring a controlled release and degradation to non-toxic products. Meanwhile, oral administration is the most convenient route for drug delivery and the focus of recent research concerns the development of carriers that can cross biological barriers such as the gastrointestinal (GI) tract. In such a way it is necessary for the carrier to protect the drug against the hostile and degrading milieu of the GI tract while increasing the residence time (e.g. bioadhesion) and target specific cells to enhance absorption which will most likely require less frequency regimens.

A number of drug delivery systems are currently under investigation to circumvent the limitation commonly found in conventional dosage forms and improve the potential of the respective drug. On the other hand, there has been a focus on the microenvironment of the cells and their interaction with these new dosage forms [8]. As a result, these new technologies have prompted the old concept of the magic bullet proposed by Paul Ehrich's vision [1]. 


\section{Type of New Drug Carriers Systems}

Microencapsulation has been important to the development of new therapeutics and has been used to produce microspheres containing both hydrophilic and hydrophobic drugs entrapped within biocompatible polymers [9]. The purpose of using these carriers is to obtain a controlled release thus maintaining therapeutic drug levels over a specified time period while reducing systemic absorption [9]. These systems have been used in food and cosmetic industry [4] and drug [10] and gene delivery [11].

Microparticles are a generic term to mention microcapsules and microspheres which can be made of polymers or lipids (liposomes) with sizes ranging from 1 to $250 \mu \mathrm{m}$ (ideally $<125 \mu \mathrm{m}$ and exceptionally $1000 \mu \mathrm{m}$ ) $[12,13]$. This technology is very important in drug delivery. Reduced doses due to higher absorption and prolonged absorption time by using adhesion properties of microparticles have been envisioned [14]. On the other hand, good in vitro/in vivo correlations have been observed [14]. Biodegradable microparticles are easily cleared by physiological systems thus avoiding the possible cytotoxicity caused by accumulation in cells and tissues. Active substances may be either adsorbed at the surface of the polymer or encapsulated within the particle. Furthermore, controlled release can be achieved by $\mathrm{pH}$ sensitive (especially useful in intravenous delivery) and/ or thermo-sensitive microparticles. Microparticles have been used to encapsulate several peptides (e.g. calcitonin and insulin), anesthetics, anti-viral drugs, hypertension and anticancer drugs [12,14], among others. There are several methods for the preparation of microparticles including the polymerization of synthetic monomers and synthesis from preformed polymers [14].

However, sub-micron size particles have shown to offer marked advantages over microparticles $[15,16]$. For example PLGA micro- and nanoparticles were compared for their uptake in caco-2 cells and revealed a higher uptake from nanoparticles ( $41 \%$ vs. $15 \%$ ) [17]. Moreover, targeting to specific tissues such as inflamed and cancerous tissues may be limited only to nanoparticles [18].

\subsection{Microsponges}

Microsponges are biologically porous inert particles that are made of synthetic polymers with the capacity to store a volume of an active agent up to their own weight [19]. They can protect the drug from the environment and provide a controlled release. Market products are available such as Retin-A micro ${ }^{\circledR}$ for acne vulgaris and $\mathrm{Carac}^{\circledR}$ containing fluorouracil for actinic keratosis treatments.

\subsection{Nanotechnology}

The use of nanotechnology for drug delivery rapidly produced commercially available products and the term nanomedicine emerged. Nanomedicine is the application of nanometer scale materials in an innovative way to develop new approaches and therapies. At this scale, materials display different physicochemical properties due to their small size, surface structure and high surface area [2]. These properties allow nanoparticulate systems to overcome current limitations of conventional formulation as they facilitate the intracellular uptake to specific cellular targets. Thus, nanotechnology has been adopted in several fields such as drug/gene delivery [20,21], imaging [22] and diagnostics [23].

\subsection{Immunoconjugates}

Antibody drug-conjugates or immunoconjugates are recombinant antibodies covalently bound through a linker to a drug [24]. The idea behind this technology is to target potent drugs to the specific site by using the specificity of monoclonal antibodies (mAb) thus avoiding nontargeted organs toxicity [24,25]. These immunoconjugates can be used across a wide spectrum of diseases by selecting the appropriate molecular domains [26]. However, initial works showed some limitations such as short half-lives, immunogenicity or even lack of efficient interaction $[25,26]$. To avoid this limitation strategies such as PEGylation, conjugation with proteins such as albumin or the use of chimeric humanized and fully human mAbs has been envisioned [26]. As a result, the first approved immunoconjugate (Mylotarg, gemtuzumab ozogamicin) was used for the treatment of acute myeloid leukemia [25]. Several other immunoconjugates are on the pipeline and in ongoing phase 3 clinical trials such as Naptumomab estafenatox for the treatment of advanced renal disease or Brentuximab vedotin for the treatment of Hodgkin lymphoma [27]. On the other hand, new strategies have been developed to use antibodies attached on nanoparticles and liposomes (so called immunonanoparticles and immunoliposomes, respectively) [22,28,29]. These systems can be applied to encapsulate multiple drugs while protecting from the external environment and exert a controlled release. Moreover, they can target hard-to-target tissues such as blood-brain barrier (BBB) by targeting transferrin, insulin or glutathione receptors, triggering their activation and consequent internalization $[20,29]$.

\subsection{Virus}

Viruses are potential vehicles for drug and gene therapies due to their natural ability to infect specific cells and transport genomic material to the nucleus [30-32]. Using recombinant virus can improve transfection efficiency [31] while evading degradation by lysosomes [32] thus enhancing drug delivery. The main difficulties involve 
creating viral vectors lacking replication machinery while maintaining the ability to infect mammalian cells [32]. Various viruses have been tested and the most common used are lentivirus, retrovirus and adenovirus [21,32]. However, the use of viruses raises concerns related to their safety due to the risk of insertional mistakes and activation of proto-oncogenes, viral replication and strong immune responses [30]. Moreover, retroviruses have size loading limitation as they can only infect dividing cells therefore they are most used for ex vivo delivery. Lentivirus on the other hand can deliver gene into nondividing cells as well as adenovirus (the virus remains extrachromosomal which reduces the chances of disrupting cellular genome) [30]. These systems are most likely to be applied in cytotoxic gene therapy [30,33]. In contrast to these, nonviral vectors such as liposomes (virosomes) and nanoparticles have rapidly increased due to their low immune response and ease of synthesis [34]. However, limitation of inefficient transfer and low gene expression have been reported and have to be overcome [31].

\subsection{Vesicular Systems}

\subsubsection{Liposomes, Transferosomes, Ethosomes, Niosomes, Virosomes, Cochleate, Cubosomes}

These are phospholipid based vehicles composed of a bilayer membrane that can be divided into small unilamellar vesicles (or SUV from $20 \mathrm{~nm}$ to $100 \mathrm{~nm}$ ), large unilamellar vesicles (LUV from 100 to $500 \mathrm{~nm}$ ) and multilamellar vesicles (MVL exceeding $500 \mathrm{~nm}$ ) [3]. These systems have the ability to encapsulate both lipophilic drugs within their membrane and hydrophilic drugs inside or outside the aqueous core and the membrane of these carriers can be altered and tuned [6]. Liposomes which are most commonly produced with phosphatidylcholine show great compatibility, ease of preparation, wide range of drug compatibilities, increased solubility of drugs (e.g. cycloporin A [35]), tuned pharmacokinetic profile and improved oral absorption. Commonly, they present difficulties when orally delivered due to the poor stability of the vesicles under the physiological conditions typically found in the GI tract $[4,35$, 36]. Liposomes can also act as a drug depot injected subcutaneously and intact vesicles were found after $96 \mathrm{~h}$. However, liposomes are metastable systems and their pharmaceutical use may be limited due to content leakage with poor controlled release, low encapsulation efficiency and loading. Moreover, weak chemical and physical protection of sensitive drugs, aggregation into large particles and hydrolysis with formation of oxidation products with difficulties in industrial scale production and stability problems during storage have been also described [3,37-39]. As a result, ethosomes and transfero- somes are liposomes with increased flexibility due to the addition of ethanol and surfactants, respectively $[3,40$, 41]. Niosomes are a non-ionic surfactant vesicles made up from polyoxyethylene alkyl ethers, polyoxyethylene alkyl esters or saccharose diesters [3]. These systems are specially designed for skin delivery (ethanol is a known permeability enhancer) due to their facilitated fusion and malleability (transferosomes are ultradeformable) with membranes and have shown that they can be modulated from superficial skin (e.g. treatment of Herpes virus) to full dermal penetration (e.g. required for transdermal delivery of insulin) [40,41] overcoming limitation commonly found in liposomes [41]. The other type of liposomes are classified as virosomes which are liposomes carrying viral proteins removed from virus on their surface. This strategy has been proposed to immunization [34] and can be administered via mucosal (nasal, vaginal, etc.), intradermal and intramuscular routes. Those systems can incorporate a variety of molecules and can be designed to improve the uptake by dendritic cells through different receptor-mediated routes [31]. Furthermore, cochleates are stable particles (more than other lipidic structures) derived from liposomes composed mainly of charged phosphatidylserine in the presence of divalent counter ion such as $\mathrm{Ca}^{2+}$ which forms a continuous large lipid bilayer sheet with no internal aqueous space [35,42, 43]. Cochleate delivery has shown potential use for amphotericin B, factor VIII delivery, proteins, peptides and DNA $[43,44]$. Finally, there are cubosomes. Because of their multilayer structure of continuous lipid bilayer cubosomes are similar to cochleates but they are considered as novel lipid delivery systems. They have self-assembly cubic-like appearance, are biocompatible and show bioadhesive properties ideal for oral administration [45,46]. Example, the oral administration of cubosomes loaded with insulin resulted in a hypoglycemic effect in rats [47]. More recently, the problems associated with the use of ultrasound in liposomes was overcome and a new kind of liposomes named eLiposomes were produced [6]. The eLiposome can be used as drug carriers which can be induced to vaporize and cavitate when exposed to ultrasound being useful in several applications such as in cancer therapy [6]. A variety of commercially available products constituted from liposomes are available such as Pevaryl ${ }^{\circledR}$ containing econazole which have been used to treat dermatomycosis, Diclac ${ }^{\circledR}$ for therapy of osteoarthritis and Daylong ${ }^{\circledR}$ containing UV filters for patients with high risk of actinic keratosis.

\subsubsection{Solid Lipid Nanoparticles (SLN) and Nanostructure Lipid Carriers (NLC)}

Solid lipid nanoparticles (SLN) are made up from lipids, solid at room and body temperature, such as glycerol 
behenate, glycerol palmitostearate, lecithin, triglycerides and tristearin glyceride [4,35]. Contrary to liposomes, SLN have shown to be stable for a long period, protect labile compounds from chemical degradation and can be processed up to large-scale production. However, they still present problems related to their loading efficiency due to the formation of a lipid crystal matrix and possible changes of the physical state of the lipids $[3,35,39]$. To overcome this limitation, a novel structure composed of a mixture of lipids solid and fluid at room temperature (semi-liquid formulations) named nanostructured lipid carriers (NLC) were produced [3]. This system shows high encapsulation efficiency and loading capacity due to the formation of less ordered lipid matrix, and they show long term stability with a controlled release and without burst effect. These colloidal carriers have emerged as a potential alternative to other recent colloidal systems like polymeric nanoparticles [35].

\subsection{Microemulsions and Nanoemulsions}

Micro- and nanoemulsions are isotropic mixtures of oil/ water stabilized by surfactants frequently in combination with co-surfactants $[3,4,41]$. They have shown high solubilization and dissolution properties, thermodynamic stability and the stabilizers prevent particle agglomeration and/or drug leakage. Thus, they have improved permeation enhancement ideal for transdermal delivery as they act in synergy [41]. Microemulsions may work by enhanced disruption of skin-lipid structure or by improving the stability of the drug in the formulation.

\subsection{Cyclodextrins}

Cyclodextrins are cyclic oligosaccharides containing at least $6 \mathrm{D}$-(+)-glucopyranose units attached by $\alpha-1,4-$ linkage. Three types of cyclodextrins are found in the nature named $\alpha$ (6 units), $\beta$ (7 units) and $\gamma$-cyclodextrins (8 units). $\beta$-Cyclodextrin is ideal for drug delivery due to the cavity size, efficiency drug complexation and loading, availability and relatively low cost $[41,48]$. They can prevent the drug degradation, improve the drug stability and solubility resulting on an higher bioavailability [4, 48]. An example of cyclodextrins in drug delivery system is the derivate 2-hydroxylpropyl ( $\mathrm{HP} \beta \mathrm{CD}$ ) which is a powerful solubilizer and has a hydrophilic outside and hydrophobic inside [48]. For absorption in the GI tract, the complexes must contact with the surface thus promoting dissociation and drug permeation across the membrane [41]. Moreover, cyclodextrins can work synergistically as permeation enhancers to improve their absorption across the skin.

\subsection{Metal Nanoparticles and Quantum Dots}

Inorganic nanoparticles have emerged a few years ago as drug and gene delivery systems, imaging agents and diagnostic biosensors [22,49]. Magnetic drug targeting (such as the use of iron) is characterized by conjugating a magnetic material under the action of the external magnetic field, which can accumulate in target tissue areas under the action of the external magnetic field $[4,23,50]$. However, magnetic particles alone are not suited for drug vehicles because of limitations in the controlled release. A mixed composition of a magnetic nucleus and a polymeric shell could take advantage of the two components [50].

Quantum dots are colloidal cores surrounded by one or more surface coatings that reduce leaching of metals from the core. These nanoparticles are of extreme importance for diagnosis.

Furthermore, titanium dioxide and zinc oxide demonstrate the potential of nanoparticles to improve therapeutic/prevention performance being particularly useful as sunscreen agents [51]. The micronization of these compounds to nanometer range removes the opacity characteristic associated with them and increases the UV protection [51,52].

Finally, gold nanoparticles have shown a selective transportation of drugs to cancer cell nucleus specially when incorporated with conjugated arginine-glycineaspartic acid peptide (RGD) and PEG [53]. When reaching the tumor cells, they can induce hyperthermia using non-invasive radiofrequency.

\subsection{Polymers}

\subsubsection{Dendrimers}

Dendrimers are tree-like branched synthetic polymer macromolecular nanoparticles in a dendron-like structure which can be designed to target specific structures [54]. They have a remarkable well-defined control over size (comparable size to proteins) with narrow polydispersity [54-56]. In addition, they have a large surface functionality providing a wide range of applications such as drug [57] and gene delivery [58], biological adhesives [59], imaging agents (e.g. MRI) [56]. Thus, they can be used for oral, transdermal, ocular and intravenous deliveries [60,61]. Moreover, dendrimers have shown that they can easily cross cell barriers by both paracellular and transcellular pathways [56]. Dendrimers can be structurally modified. This modification can be made to the nature of the core and the scaffold giving polyfunction capacity to the dendritic structure. This can be copulated to an antibody and its production can be through divergent and convergent routes or other techniques such as self-assembling synthesis, lego chemistry and click chemisty $[54,57]$. Their size, molecular weight and number of surface functional groups can be modulated through the increase in generation number ( $1 \mathrm{~nm}$ per generation) [56, 
57]. In general, dendrimers are terminated with amine surface groups (G1, G2, G..) but can also be terminated with carboxylate (G1.5, G2.5, G..) [62]. Moreover, the interior is characterized by the availability of a wide amount of solvent-filled void space that can accommodate the drug [56]. Additionally, dendrimers are non-immunogenic and are small enough to escape the vasculature and target tumor cells. Their size can be tailored to be below the threshold for renal filtration [55]. There are several systems available such as poly(amidoamine) PAMAM, poly(etherhydroxylamine)-PEHAM and poly (propyleneneimine)—PPI, and phosphorous containing dendrimers [56]. PAMAM is the most used dendrimer due to the fact that it provides a large range of reactive sites for the conjugation for drug or other chemical moiety complexation [55,57]. Dendrimers provide a high loading capacity with controlled release which can be modulated to actively release the agent by $\mathrm{pH}$-triggering cleavage. The rate of drug release from the matrix is influenced by the nature of the linking bond or spacer between the drug and scaffold and the targeted physiological domain for intended release. The surface ligands can also control the release from the dendrimers such as increased steric hindrance of mannose and folate.

A novel concept that enables simultaneous release of all functional groups by a single stimulus has been reported which has been named cascade-release dendrimers (or dendrimer disassembly or self-immolative dendrimers). However, this system raises concerns about drug release at the wrong time and place which can raise toxicity profiles [56]. Several dendrimer-based diagnostic and/or in vitro technologies are already in the market such as Stratus CS which is a dendrimer-coupled antibody reagents [63], Superfect (activated dendrimer technology for DNA transfection into a broad range of cell lines) [64] and Priofect ${ }^{\mathrm{TM}}$ which is a transfection reagent [65]. Priostar ${ }^{\mathrm{TM}}$ and STARBURST ${ }^{\circledR}$ have also been designed to be used as targeted diagnostic and therapeutic delivery systems for a wide variety of drugs to cancer cells and other diseases [66,67]. As well, Vivagel ${ }^{\circledR}$ is a microbicide for prevention of HIV and HSV and it is based on dendrimers [68].

\subsubsection{Natural and Synthetic Polymeric Nanoparticles}

Drug/gene encapsulation can be achieved by embedding into the matrix or absorbed onto the surface of nanoparticles homogenously dispersed or not. As for the microparticles, the term nanoparticles is a collective name for both nanospheres and nanocapsules [16]. Nanoparticles are solid carriers that can be either made up of natural or synthetic polymers and whether or not biodegradable [16]. Nanoparticles have received more attention than have liposomes because of their therapeutic potential and greater stability in biological fluids as well as during storage [69]. Nanoparticles are advantageous in many ways since they use the unique micro-anatomy of the inflamed tissue blood capillaries, which have gaps between the lining of endothelial cells causing vessel leakiness. Moreover, they show high encapsulation efficiency and protection of instable drugs against degradation of the external environment in comparison to liposomes [3,70].

Several methods have been described and nanoparticles can be obtained by polymerization of a monomer or from pre-formed polymers [16] but recent methods make use of safe solvents with industrial application.

The nanoparticles properties can be tailored by using different polymers and co-polymers or proteins. The new strategies use new biodegradable synthetic polymers and modified polymers from natural products such as chitosan and albumin. Chitosan has been shown to be relatively safe and is used as a food additive. Moreover, chitosan is widely used due to its biocompatibility, mucoadhesiveness and permeability enhancing properties [35, 71,72] and its derivates have shown improved characteristics. Albumin is a natural carrier of hydrophobic molecules such as fatty acids, hormones and fat-soluble vitamins. Albumin has been extensively used as it is nontoxic and non-immunogenic.

However, natural polymers raise concerns in purity and stability and thus synthetic polymers have been applied. Synthetic polymers from the ester family such as poly(lactic acid) (PLA), poly(cyanoacrylates) (PACA), poly(acrylic acid), poly(anhydrides), poly(amides), poly (ortho esters), poly(ethylene glycol), and poly(vinyl alcohol) (PVA) and other like poly(isobutylcynoacrylate) (PIBCA), poly(ethylene oxide) (PEO), poly( $\varepsilon$-caprolactone) (PCL) are suitable for drug delivery due to their biodegradability. They can be conjugated between them to form different structures with different properties such as controlled release profiles and strong cell biocompatibility. In fact, PLGA, another synthetic polymer, has been extensively used in medical applications such as suture materials [73] and bone fixation nails and screws [74] as well as in diverse drug delivery applications [20, 75,76]. It is biocompatible and biodegradable forming compatible moieties of lactic acid and glycolic acid which are further removed by the citric acid cycle [2]. As this process is slow it does not affect normal cell function [2,71].

Recently, $\operatorname{poly}(\beta$-amino ester) (PbAE) has emerged in the spotlight because it demonstrates a $\mathrm{pH}$ sensitive release $[7,77,78]$ in which at acid $\mathrm{pH}$ it rapidly releases its contents. This polymer has shown to be less toxic than other cationic polymers such as poly(ethyleneimine) and poly(L-lysine) (PLL) [78]. PbAE are insoluble at phy- 
siological $\mathrm{pH}$ but become instantly soluble in aqueous media when the $\mathrm{pH}$ of the solution is reduced below 6.5. These agents are useful for therapeutics in the vicinity of tumor mass $[77,78]$ and for others they must escape endosomal compartmentalization prior to fusion with lysosomes [78].

\section{General Mechanisms Consideration}

\subsection{Surface Functionalization, Controlled Release and Tissue-Targeting Design}

A number of methods have been investigated to target drugs to a specific site of interest either by passive (increased accumulation due to passive physiological factors) or active diffusion (use of ligands to specific target) [6].

Surface modification of drug carriers with bioactive molecules that can be adsorbed, coated, conjugated or linked to them which interact with cell receptors demonstrate a selective affinity for a specific cell or tissue type and can subsequently enhance drug uptake (Figure 1). The modified-coating (e.g. combined albumin and chitosan) can also be used to prevent enzymatic degradation both on the GI tract and plasma [72]. Monoclonal antibodies (or fragments) or non-antibody ligands like carbohydrates specific for cell surface such as lectins have been investigated [79]. Also, most recently small molecules or peptides agonists/substracts or antagonists/inhibitors for receptors that are overexpressed on cell surface of specific tissue (e.g. folate, transferrin as well as galactosamine) have shown promising results $[6,54,79,80]$. Several considerations have to be taken as the use of targeting ligands which can enhance distribution to secondary target sites of non-intended tissues [54]. In fact, the disadvantage of using non-antibody ligands is their nonselective expression [79]. On the other hand, immunoconjugates poses problems related to immunogenicity and retention in the reticuloendothelial system (RES) [55].

The carrier surface modification can also incorporate coatings to change the lipophilicity/hydrophilicity profile, prevent the uptake by immune cells and improve cell recognition (e.g. the synergy between the distribution and signaling of antibodies). As a result, per example, once IV injection occurs, nanoparticles are cleared from the plasma within a few minutes due to opsonization and subsequent phagocytosis by the cells of the RES [81]. Opsonization can be reduced by applying some surface ligands. An example is PEG, a hydrophilic polymer, which promotes the resistance to the binding of plasma proteins and prevents aggregation induced by salts and proteins in the serum [21]. This fact prevents opsonization and recognition from phagocytes and thus avoiding immune responses. Moreover, PEG can also reduce the access of enzymes to dendrimers scaffold and can therefore reduce their degradation [54]. In fact, in vivo nanoparticles and liposomes coated with PEG increase circulation time from several minutes to many hours and enhance residence times up to 200-fold in humans [82-84]. On the other hand, the effectiveness of PEG depends on surface density, chain length [85] and ability to avoid the liver uptake. However, PEG carriers are intended for intracellular penetration and sometimes PEG prevents normal interactions of the carrier with cells. Also, PE-Gylated nanocarrier systems have shown to induce an immune response, known as the accelerated blood clearance (ABC phenomenon) after repeated injection with subsequent increased accumulation on the liver and spleen [86].

Thus, new strategies have been pursued such as replacing PEG with polyamino acid polyhydroxyethyl-Laspargine (PHEA). This strategy demonstrated favorably long circulation times and reduced ABC phenomenon compared to PEG [86]. Moreover, using a hydrazonecholesteryl hemisuccinate linkage to the PEG which could be cleaved by esterases showed $\mathrm{pH}$-response at $\mathrm{pH}$ 5.5 (with a $t_{1 / 2}$ of $6.7 \mathrm{~h}$ ) and was stable at physiological $\mathrm{pH}$ (with a $\mathrm{t}_{1 / 2}$ of $40.9 \mathrm{~h}$ ) and thus can be used for tumor targeting [86]. Additionally, PEO (poly(ethylene glycol) and its derivates also promote stealth shielding and prolonged circulation $[7,78,87]$ and have been extensively used as biomaterials due to excellent biocompatibility and low toxicity [78]. PLA and PLGA have also demonstrated some stealth shielding [16]. All these systems can also be used as promoters of GI absorption [88].

Another key factor to improve the carrier targeting is the surface charge (zeta potential). This determines the interaction with plasma proteins, cell membranes and surface, thus ultimately affecting clearance and distribution patterns [54,79,89]. For instance, cationic surfaces (obtained per example by chitosan coating) demonstrate a strong interaction with cell membranes and surfaces due to their overall anionic charge [54]. However, PLGA nanoparticles are slightly negative at the surface and this tends to limit their interaction with both negatively charged plasmids and their intracellular uptake [71].

After reaching the cell, the drug release can be made from two different mechanisms including release from the carrier as well as absorption from the cell and the carrier can be taken into the cell and slowly release its contents [79]. Nanoparticles are absorbed by different mechanisms but endocytosis is the most significant contributor to cell entry [54,90]. Caveolae-mediated endocytosis is thought to be the primary uptake mechanism for particles above $200 \mathrm{~nm}$ [90] but also lipid raft-associated receptors [90], actin and clathrin, microtubules, and cholesterol-dependent process might be implied in 
the nanoparticle uptake mechanisms $[54,90]$. The surface charge is a key factor as anionic dendrimers were endocytosed by clathrin dependent processes (with promotion of tight junction opening) but were independent of caveolin-mediated endocytosis.

Earlier research on internalization of PAMAM dendrimers showed that the interaction was mediated by electrostatic interaction between the cationic primary amine surface groups and the negatively charged proteoglycans displayed on the surface of mammalian cells which trigger macropinocytosis and clathrin-mediated endocytosis [57].

When considering this uptake by cells, they have to be designed to avoid the acidic environment of lysosomes which are the common degradation pathway of nanoparticles inside the cell [90]. Moreover, once dendrimers saturated the lysosomal pathway, they were eventually found in endosomes [54]. Recent advances taking advantages of the microenvironment of the cell have been investigated and new carriers can reach the nucleus (gene therapy) or other organelles involved in the disease state leading to a direct release of the loading drug in considerable concentrations at the specific site [90].

Another approach is the use of an external stimulus to increase cellular ability for drug uptake such as ultrasounds to temporarily increase the junctions between cells. Here eLiposomes may find a potential use [6]. Passive targeting refers to the increased accumulation of drug or drug-carrier at a particular site due to passive physiological factors. For cancer therapy, this typically includes taking advantage of enhanced permeability and retention (EPR) [6].

On the other hand, a major problem associated with the new drug carriers is their release profile because these can be associated with burst releases [91]. While burst releases are useful in dermal and systemic delivery, they may lead to a significant and unpredictable toxicity especially for potent drugs and treatments of chronic diseases. Several strategies have been proposed and controlled release can be achieved by bi-association of liposomes encapsulated inside a polymeric particle [92] as well as chitosan associated with alginate which demonstrate a controlled release and prevention of burst release [93]. Similar strategies can be achieved by using microparticles containing nanoparticles [91]. Also changing some technological features such as production method [91] and use of surfactant can promote different control release [91].

Other technological features include deficient heterogeneous drug distribution (e.g. surface-associated drug), temperature of solvent removal, the physicochemical nature of the polymeric matrix (use of non water soluble polymers to avoid water uptake), porosity and recovery method as well as the concentration of drug incorporated [94-97], among others.

\subsection{Combined Therapy by Simultaneously Encapsulated Drugs}

These are systems that have the potential to deliver more than one drug at once. For example, PLGA nanoparticles were simultaneously loaded with vincristine sulfate and verapamil hydrochloride to deliver the effective chemotherapeutic agents while inhibiting P-gP efflux system. This system allows overcoming tumor lack of sensitivity and increases therapeutic index. As a result, the same strategy was planned for delivery of doxorubicin and cyclosporine A [98,99]. However, recent studies suggest that PLGA-PEG interact with P-gP [20] and this could improve the efficacy of this system. The design of these types of systems has to take into consideration the characteristics of the drugs to be encapsulated. Example, hydrophobic drugs are more likely to be encapsulated in hydrophobic polymers and vice-versa [95]. To overcome this limitation, synthesis of new polymers such as (PLAPEG-PLA) $)_{n}$ or PCL-PEG can be produced [95] and retinoic acid (hydrophobic) and calf thymus DNA (hydro-
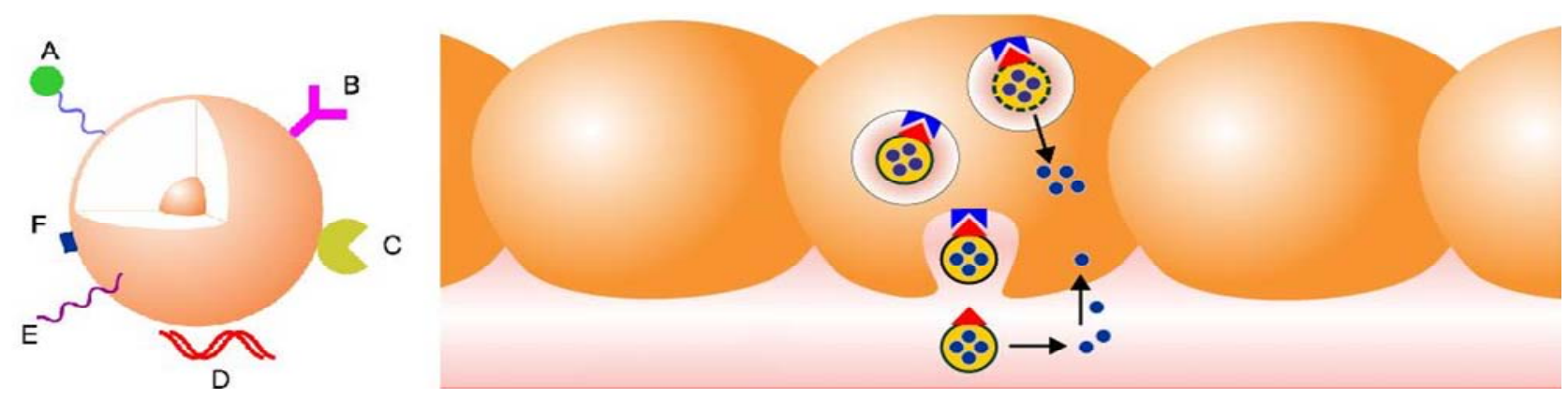

Figure 1. Different possibilities for nanoparticles specific targeting. In the left nanoparticle functionalized with: (A) protective polymer with targeting ligand/probe copulated; (B) Antibody; (C) Enzyme; (D) Complexation with DNA; (E) protective polymer; (F) ligand; In the right: nanoparticles can either release their content after cell internalization or near the cell after targeting a specific receptor. 
philic) were both encapsulated in this system with satisfactory loading [95]. Another strategy is to have two different release rates of the two drugs to improve treatments (such as cancer treatment). In fact, a paclitaxel and a C6-ceramide were encapsulated in a controlled blend polymer of PLGA-PbAE to effectively overcome the cancer drug resistance mechanisms [7].

\subsection{Carrier Distribution}

As stated above the RES mainly in the liver and spleen are the major obstacles to carrier systems due to their ability to internalization and removal from systemic circulation [16]. In fact, after IV administration of PLGA nanoparticles, the majority were found in the liver (about $40 \%)$ followed by kidney (26\%), heart (12\%) and brain (13\%) and only a small amount was found in the plasma [2]. Similar results were obtained with PLGA-PbAE [7].

The route of administration is also important for the distribution pattern as after IP injection for all types of charged particles due to lymphatic clearance [49]. Moreover, lipophilicity of carriers influence the uptake from cells and as a result more hydrophilic particles may be rapidly eliminated [16].

The medium $\mathrm{pH}$ modulates surface charge thus changing cellular uptake and subsequently the distribution of the carrier through the system [71]. The nanoparticles charge surface and route of administration were further explored by using $10 \mathrm{~nm}$ Gold nanoparticles functionalized with different groups aiming different zeta potential (neutral, negative, positive and zwittteronic) by IV and IP administrations. Following IV injection, a 10 fold lower peak plasma concentration was observed with positive charged particles and clearance within 15 minutes was more pronounced for negative and positively charged particles [49]. On the other hand, after IP injection low concentrations of both negative and positive charged particles were found [49]. These results evidence that neutral and zwitteronic nanoparticles show enhanced circulation. These marked differences in bioavailability could be primarily due to opsonization of the nanoparticles with antibodies for recognition by resident macrophages [49] and the same effect was observed in dendrimers [54].

Nanocarriers can be modulated to deliver drugs to specific tissues and organs. Branching size of dendrimers can be modulated to determine their distribution and elimination throughout the body. Thus, they can avoid renal clearance with a cut-off of 40 - $60 \mathrm{kDa}$ which is approximately the G7 [54,56]. From G1 to G5 the dendrimers are rapidly cleared to the kidneys/bladder and from G3 - G7 they are mainly seen in circulation while G8 are found in the lymph node and, finally, superior to G9 are found in the liver [56].
As stated previously, PEG influences the distribution of the carrier in the body. In general, as the molecular weight of the PEGylated dendrimers increases, uptake from the injection site into the lymph becomes a more important contributor to the overall absorption profile, revealing potential drug delivery systems as well as improved lymphatic system imaging agents [54].

\section{Pharmaceutical Applications}

\subsection{Brain Delivery}

The blood brain barrier (BBB) is an extraordinary gatekeeper toward exogenous substances being estimated that $98 \%$ of all drug never reach the brain in therapeutic concentrations [23]. There have been several experimental strategies to address these problems and enhance brain bioavailability of existing therapeutics into the CNS [100]. These included injecting drugs directly into the brain or CSF (intraparenchymal or intracerebral administration), various implants or convection-enhanced delivery, slow-release devices, transient disruption of the BBB such as MRI-guided focused ultrasound and chemical or osmotic modulation of tight junctions - with the use of hyperosmotic solutions of saccharides (e.g. mannitol) or vasoactive compounds (e.g. RMP-7) [84,101].

Overall, the idea of using an appropriate drug carrier to delivery across the BBB is reinforced. Nanovectoring with tissue-specific targets is an ideal pathway since it delivers both hydro-and lipophilic drugs, as well as macromolecules such as peptides and genes through a controlled release profile over an extended period of time [5, 81,102]. Since nanoparticles are small in size, they easily penetrate into small capillaries and through the physical restrictions presented by the brain interstitial space. Consequently, they can be transported within cells, allowing an efficient drug accumulation at targeted sites in the body [81,102]. However, nanoparticles cannot freely diffuse through the BBB and require receptor-mediated transporters [103]. Hence, the use of the specific peptides for targeting the receptor-mediated transcytosis across BBB can be a successful strategy for improving drug delivery to the brain [5]. In this way, promising results have been achieved by directly delivering drugs to the brain interstitium through the design of polymer-based drug delivery systems $[102,104]$.

Different approaches have been pursued and in recent researches using the combination of two techniques such as improvement of target-specificity and bioavailability $[5,101]$. Antibodies for different receptors, chimeric peptides fused molecules [101], pro-drugs resembling the natural ligands, viral vectors [105] and nanoparticles are the most common techniques [5,103].

In nanoparticle field, dalargin or loperamide-loaded 
PBCA nanoparticles coated with polysorbate 80 showed a pronounced analgesic effect in comparison with that of free drug [106]. Several mechanisms were proposed and endocytosis and transcytosis mediated by carriers were evidenced, as nanoparticles were overcoated with Apo-A, $B, C, E$ or J. The effect was only achieved when ApoB or $\mathrm{E}$ were in the coating surface. In this study, polysorbates (and also poloxamers) can act as an anchor for several Apo which are then able to interact with the LRP recaptor, before being taken up by the microvessel endothelial cells via receptor-mediated endocytosis $[80,85,107,108]$.

Another approach to LRP receptor is by the use of a series of peptides called "angiopep" at the surface of nanoparticles which have shown specific targeting of the LRP $[109,110]$. The most used is angiopep-2 as it shows enhanced transcytosis across the brain and it has been effective against glioblastoma [109,111].

Other receptors that have been proposed to targeting are insulin, albumin, transferrin, lactoferrin [110] and more recently, the glutathione receptor [20]. In the last case, liposomes were coated with glutathione-conjugated PEG (G-Technology ${ }^{\circledR}$ ) and they successfully delivered free drug (doxorubicin or ribavirin) [83,101]. For all the reasons stated, in 2010, EMA granted an orphan designation (EU/3/10/781) for the GSH-PEG liposomal doxorubicin hydrochloride for the treatment of glioma [112].

\subsection{Mucosal Drug Delivery}

The oral route is the most desirable route for the administration of drugs as it is simple and free from complications arising from more invasive methods. When designing such formulation, several parameters have to be accessed as charges from the carrier system and content, the solubility of the drug carrier, among others. Those factors will ultimately alter their uptake from mucosal membranes. Moreover, mucosal surfaces are typically efficiently removing the drugs by mucus clearance mechanisms and the GI tract acts as a physiological and chemical barrier posing several challenges. Also, the drug can cause irritation and limit its use by this route.

To overcome these limitations, several methods have been investigated and nanoparticles are also a useful tool in mucosal delivery. It has been shown that they can protect protein and peptide drugs from enzymatic degradation and increase their low permeability across the intestinal epithelium and circumvent efflux processes [54, $62,69,72,113]$. Specifically, nanoparticles can be taken up by increased residence time in the enterocytes [16], by targeting to $\mathrm{M}$ cells $[114,115]$ or by specific targeting receptors at the surface. In this area, polymers play a crucial function. Example, chitosan possesses marked mucoadhesive properties to the mucosal surface and can transiently open the tight junctions between mucosal cells (an effect also observed for PAMAM dendrimers) $[62,99,113]$. As a result, nanoparticles composed of chitosan loaded with insulin have been able to enhance intestinal absorption in vivo $[72,116]$.

Furthermore, oral vaccination has gained new insights and several studies have been performed [117]. Oral immunization has been making use of live attenuated organisms [118] or the use of peptides [114] and recently based on DNA vaccines [119]. However, there are still limitations for effective oral immunization such as the failure to swallow the vaccine, inactivation in the GI tract or interference with gut flora [69]. Promising results have been obtained and humoral and cellular in vivo responses have been observed through the use of specific ligands (e.g. RGD peptide) to target M cells [114,115]. In addition, immunization with carriers may be ideal when the antigen of interest is not immunogenic enough. $\mathrm{PbAE}$ microparticles on their own can activate dendritic cells [77] acting as an immune-stimulating complex and as a result, PLGA-PbAE microparticles were able to induce antigen-specific rejection of transplanted synergetic tumor cells.

Furthermore, nasal vaccination has been investigated as a promising route for vaccination. PLGA blended with different stabilizers [76] and cochleates [44] demonstrated good in vivo vaccination, capable of overcoming nasal cell membranes. As well, genetic vaccination has the potential to treat and prevent several diseases for which conventional vaccines are ineffective and limited [77]. The use of a carrier to specifically target APC cells may show promising advantages while protecting the encapsulated genetic material [77].

Gene delivery to desired cells involves the concept of delivery the gene for expression (e.g. production of proteins that play a role in drug) or the use of siRNA (to target a specific mRNA expression) $[30,120]$. The use of carriers allows the entry of these genetic materials to the cells that otherwise would be destroyed by enzymes and due to their small size and high density are easier to transfer into cells. As stated, viral vectors are effective although raising certain concerns, but synthetic systems have higher flexibility and safety profiles [30]. An ideal gene delivery carrier would be a system that can safely transport the genetic materials without exhibiting any toxicity and immune responses as well as being able to be produced on large scale [120]. Using virosomes, these can be processed by APC cells which ensures presentation via MHC I or II resulting in humoral and cellular responses [34]. A commercially available product is Epaxal ${ }^{\circledR}$ [121] which compared to conventional aluminum-adsorbed hepatitis A vaccine, the virosome-based vaccine may provide enhanced protection and cause fewer local adverse effects [34]. Other products based on the same 
concept are PEVION's virosomes for influenza virus [122]. Using cationic modified particles (such as chitosan and derivates such as mannosylated chitosan), genetic material can bind and condense through electrostatic interactions [123]. Recently, PEI polymer has been extensively used both in vitro and in vivo. PEI is the most effective nonviral carrier with high transfection capacity and ability to escape from endosomes [31,120,124]. In fact, ExGen $500^{\mathrm{TM}}$ technology (linear PEI condensed with genetic material) has been shown to interact with cell surface proteoglycans resulting in internalization by endosomes after which PEI acts as an effective proton sponge buffer protecting the genetic material from lysosomal degradation [32,124]. This proton sponge effect is due to PEI primary and secondary amines that lead to an influx of counter ions (chloride) that enhances osmotic pressure and eventually burst the endocytic vesicle. Other mechanism has been proposed in that PEI weakened the endosome membrane thus preventing fusion with lysosomes [124].

Another area of interest is the antibiotics and antiviral therapy using those drug carrier systems. Again, nanocarriers are ideal, as they can overcome the defense mechanisms, can result in higher uptake to the site and exert better results than the free drug. They may also be suitable to target drugs where the free drug would not permeate into (e.g. BBB). Anticancer drug using gold nanoparticles have shown antibacterial and antifungal activity against gram-negative bacteria [50]. Amphotericin B PLGA nanoparticles, taken both orally and IV, were more effective in reducing the lung burden in murine models of pulmonary and disseminated aspargilosis than commercial available formulations [125]. AmBisome ${ }^{\circledR}$ is a liposomal preparation of amphotericin B that is administered by IV injection and has been effective in the treatment of cryptococcal meningitis in HIV-infected patients, Aspergillus Candida and/or Cryptococcus species infections refractory to amphotericin B deoxycholate [36]. Recently, VivaGel ${ }^{\circledR}$ by Starpharma Pty Ltd. has been investigated as a vaginal microbicide for the prevention of HIV and HSV infections [68,126] using dendrimer technology (SPL7013). The highly charged surface allows SPOL7013 to attach to targets on viruses, blocking viral attachment and/or adsorption to cells thereby preventing infection. In the case of HIV, SPL7013 is thought to bind gp120 proteins on the surface of the virus [126]. It has been able to inhibit by $<99 \%$ HIV infection of human macrophages in vitro, and to protect Vero cells from HSV-2 infection, and effectively to block vaginal transmission of SHIV [126].

\subsection{Pulmonary Drug Delivery}

The pulmonary route requires a suitable design as the deposition of the nanoparticles differs according to the particle size [69]. On the other hand, the mucus may restrain the entry of nanoparticles. PSA-PEG nanoparticles were able to penetrate and diffuse in sputum expectorate from lungs of cystic fibrosis patients and this system could be used to improve drug therapies in various mucosal surfaces [88].

\subsection{Skin Drug Delivery}

Application to the skin desires two effects: transdermal and topical effects. The transdermal delivery has gained a significant importance for systemic treatment as it is able to avoid first-pass metabolism and major fluctuations of plasma levels typical of repeated oral administration. SLN, due to an initial burst release followed by water evaporation, proved to penetrate human and pig skin ex vivo more rapidly and to a higher extent than conventional dosage forms and a nanoemulsion [3]. The same results were observed for SLN and NLC incorporating red nile (4 fold enhancing). The rapid degradation of those systems may promote contact with the skin and the occlusion may promote drug uptake. Additionally, SLN were able to induce epidermal drug targeting for prednicarbate [127] and podophyllotoxin [128]. Other drug carriers have been used in skin drug delivery. Example, transfersomes with ketoprofen $\left(\right.$ Diractin $^{\circledR}$ ) [129] were applied as a transdermal system in a multicentre, randomized, double-blind trial and showed similar efficacy in relief of knee osteoarthritis compared to celecoxib. In addition, liposomes tend to fuse at the skin surface [3] and marked changes can be induced in the horny layer depending on the phospholipids used as intercellular deposition can occur and destroy lipid membranes [3]. Antifungal drugs are of special interest and although current formulations cure the majority of the problems an econazole liposome formulation in vitro has shown better cure rates [3]. In general, percutaneous drug absorption appears to be increased via association with dendrimers due to their ability to interact with lipid bilayers in the skin [54]. Moreover, targeting specific areas of the skin can be tailored. As an example, OMC-coated PCL nanoparticles were found 3.4 fold greater in the stratum corneum compared to an emulsion.

Finally, the role of skin appendages is sometimes neglected due to the fact that they only represent $0.1 \%$ of the skin surface [130]. It was found that microparticles ranging from 3 - $10 \mu \mathrm{m}$ selectively penetrate the follicular ducts, whereas particles larger than $10 \mu \mathrm{m}$ remain randomly distributed in the hair follicles and stratum corneum [130]. Moreover, $5 \mu \mathrm{m}$ PLGA microparticles were visualized in the follicular ducts, while $1 \mu \mathrm{m}$ was randomly distributed into the stratum corneum and hair follicles. 
Recently, a new study performed a similar experiment and $200 \mathrm{~nm}$ were able to aggregate and penetrate along the follicular duct and this was the major penetration pathway [131] displaying an increasing interest for a potential vaccination therapy. On the other hand, $40 \mathrm{~nm}$ nanoparticles were able to enter Langerhans cell in the hair follicles while 750 and $1500 \mathrm{~nm}$ could not. The 40 $\mathrm{nm}$ nanoparticles were able to penetrate deep into the hair follicle while 750 and $1500 \mathrm{~nm}$ aggregate in the infundibulum of human hair follicles and could not target the pilosebaceous unit [132]. Smaller molecules with a ranging diameter between 7 and $20 \mathrm{~nm}$ were tested in skin permeation and were found almost exclusively in the hair follicle infundibulum and below. On the other hand, polystyrene nanoparticles ranging from 20 to 200 $\mathrm{nm}$ were found in the follicle openings [133]. Furthermore, liposomes showed that they can target the pilosebaceous unit rich in Langerhans cells and gained interest in immunizations.

\subsection{Cancer Delivery}

Cancer delivery presents a challenging obstacle for every dosage forms. Targeting cancer cells while avoiding damage to other cells is the main endeavor of cancer therapy. Major clinical obstacles raised to chemotherapeutic agents are due to large body distributions, multidrug resistance mechanism (MDR), poor absorption, increased metabolism and excretion while having poor diffusion through the tumor mass which constitutes the impaired delivery $[7,89]$. Herein, the concept of enhanced permeability and retention (EPR) in the solid tumor [134] and the microenvironment of the tumor (physiological drug resistance) [8] plays a vital role to the enhancement of nanoparticles' uptake.

PEG has been a key agent in long circulation of carriers and has shown the ability to passively accumulate in tumor tissue via EPR effect [7,8,49,54]. In addition, the lower $\mathrm{pH}$ observed (pH 6.5) in some tumors create a $\mathrm{pH}$ gradient that hinders the permeation of drugs and consti- tutes one of the causes of chemotherapy failure. PbAEPEO, a pH sensitive polymer shows a 5.2 fold higher concentration of Paclitaxel when compared to the aqueous solution [87]. Thus, it can be considered as an ideal carrier to overcome the $\mathrm{pH}$ gradient barrier. Moreover, using PLGA-PbAE nanoparticles with ceramide incurporating paclitaxel demonstrates higher accumulation within the tumor [7].

Another way to achieve selectivity of tumor cells is by using antibody-directed enzyme prodrug therapy (ADEPT). This technique involves a two-step approach to cancer therapy in which an immunoconjugate composed of a mAb-enzyme is administered to be localized within the tumor mass. Then, it is allowed to clear from the systemic circulation over time and once the ratio of tumor/ non-tumor is sufficiently high a prodrug (anticancer agent) is given (Figure 2). After reaching the tissue, it is mostly converted in tumor cells and consequently exerts local effects [25].

On the other hand, fenestration within the new vasculature (angiogenesis) is observed exhibiting pores of 200 - $400 \mathrm{~nm}$ [7] or with an upper limit of $12 \mathrm{~nm}$ in the blood-brain tumor barrier [135]. So, dendrimers nanoparticles ranging between 7 - $10 \mathrm{~nm}$ were developed to deliver therapeutic concentrations across the tumor blood brain barrier protecting from leakage to normal tissues [135].

Using specific ligands is another approach to target tumor cells and the high-affinity folate receptor, known as the folate-binding protein, has been used as a target for the delivery of a carrier containing folate at the surface to target drugs to cancer tissue. The folate receptor is overexpressed in breast, ovary, endometrium, kidney, lung, head and neck, brain and myeloid cancers [55]. In vivo, liposomes as well as PAMAM dendrimer conjugated with folate acid have shown higher efficacy (10-fold) and lower toxicity compared to those of free drug [55].

Other ligands have been used to target more specifically such as LHRH coupled carrier to deliver siRNA to

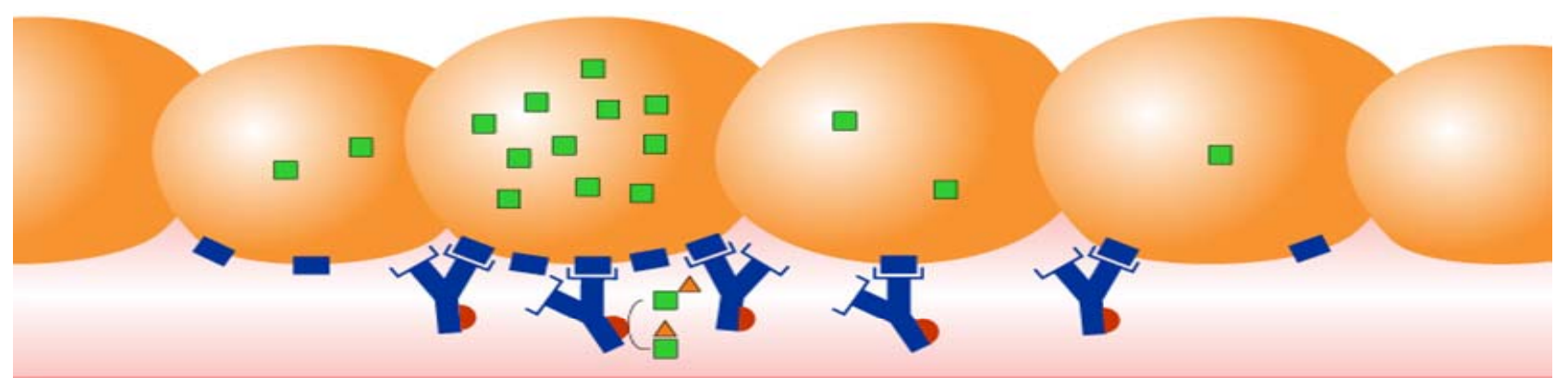

Figure 2. Antibody-directed enzyme prodrug therapy (ADEPT). Higher concentrations are found in cells overexpressing a receptor. The antibody localizes the enzyme at the tumor mass and after the intake of a prodrug it will be converted near the tumor cells. 
cancer cells [21] and N-acetylgalactosamine (NAcGal) coupled to G5 dendrimers to hepatic cancer cells [57], among others.

The use of drug carriers systems can also be used for topical tumor cancer such as melanoma. Example, 5fluorouracil niosomes increased the penetration in the stratum corneum by 8 fold. The cytotoxicity for the melanoma increased resulting in more efficiency and less irritancy than when incorporated to microsponges [3].

\section{Concluding Remarks}

As seen, the effort to produce these new drug carrier systems is clearly high. Undoubtedly, those carriers provide the hope to treat and diagnose several diseases. Several technologies have advanced into clinical studies and are nowadays market products that have been shown favorable results. It was also shown in this review that these recent drug carriers are a promising set of technologies that already penetrated the cancer area and they likely have a strong impact in this field in the future. In fact, the rationale development of anticancer carriers will provide new ways of treatment, circumventing current limitations for conventional dosage forms. However, there are some issues that need to be understood in order to ensure their safety and effectiveness. Nevertheless, in the future, new entities will become available and responsive and "clever" polymers will offer new perspectives for the treatment of diseases.

\section{REFERENCES}

[1] R. Haag and F. Kratz, "Polymer Therapeutics: Concepts and Applications," Angewandte Chemie International Edition, Vol. 45, No. 8, 2006, pp. 1198-1215. doi:10.1002/anie.200502113

[2] B. Semete, L. Booysen, Y. Lemmer, L. Kalombo and L. Katata, "In Vivo Evaluation of the Biodistribution and Safety of PLGA Nanoparticles as Drug Delivery Systems,” Nanomedicine, Vol. 6, No. 5, 2010, pp. 662-671. doi:10.1016/j.nano.2010.02.002

[3] H. C. Korting and M. Schafer-Korting, "Carriers in the Topical Treatment of Skin Disease," Handbook of Experimental Pharmacology, Vol. No. 197, 2010, pp. 435-468.

[4] S. Wang, M. Tan, Z. Zhong, M. Chen and Y. Wang, "Nanotechnologies for Curcumin: An Ancient Puzzler Meets Modern Solutions," Journal of Nanomaterials, Vol. Vol. 2011, No. 2011, p. 8.

[5] A. V. Kabanov and E. V. Batrakova, "New Technologies for Drug Delivery across the Blood Brain Barrier," Current Pharmaceutical Design, Vol. 10, No. 12, 2004, pp. 1355-1363. doi:10.2174/1381612043384826

[6] J. R. Lattin, D. M. Belnap and W. G. Pitt, "Formation of Eliposomes as a Drug Delivery Vehicle," Colloids and Surfaces B: Biointerfaces, Vol. 89, 2011, pp. 93-100.

[7] L. E. van Vlerken, Z. Duan, S. R. Little, M. V. Seiden and M. M. Amiji, "Biodistribution and Pharmacokinetic Analysis of Paclitaxel and Ceramide Administered in Multifunctional Polymer-Blend Nanoparticles in Drug Resistant Breast Cancer Model," Molecular Pharmaceutics, Vol. 5, No. 4, 2008, pp. 516-526.

doi:10.1021/mp800030k

[8] R. Li, L. Xie, Z. Zhu, Q. Liu and Y. Hu, "Reversion of pH-Induced Physiological Drug Resistance: A Novel Function of Copolymeric Nanoparticles," PLoS One, Vol. 6, No. 9, 2011, p. e24172. doi:10.1371/journal.pone.0024172

[9] C. J. Thompson, D. Hansford, S. Higgins, C. Rostron and G. A. Hutcheon, "Evaluation of Ibuprofen-Loaded Microspheres Prepared from Novel Copolyesters," International Journal of Pharmaceutics, Vol. 329, No. 1-2, 2007, pp. 53-61. doi:10.1016/j.ijpharm.2006.08.019

[10] S. Jhunjhunwala, G. Raimondi, A. W. Thomson and S. R. Little, "Delivery of Rapamycin to Dendritic Cells Using Degradable Microparticles," Journal of Controlled Release, Vol. 133, No. 3, 2009, pp. 191-197. doi:10.1016/j.jconrel.2008.10.011

[11] S. Lee, S. C. Yang, C. Y. Kao, R. H. Pierce and N. Murthy, "Solid Polymeric Microparticles Enhance the Delivery of siRNA to Macrophages in Vivo," Nucleic Acids Research, Vol. 37, No. 22, 2009, p. e145. doi:10.1093/nar/gkp758

[12] E. Allemann, J. Leroux and R. Gurny, "Polymeric Nanoand Microparticles for the Oral Delivery of Peptides and Peptidomimetics,” Advanced Drug Delivery Reviews, Vol. 34, No. 2-3, 1998, pp. 171-189. doi:10.1016/S0169-409X(98)00039-8

[13] P. Couvreur and F. Puisieux, "Nano- and Microparticles for the Delivery of Polypeptides and Proteins," Advanced Drug Delivery Reviews, Vol. 10, No. 1993, pp. 141-162.

[14] S. Freiberg and X. X. Zhu, "Polymer Microspheres for Controlled Drug Release," International Journal of Pharmaceutics, Vol. 282, No. 1-2, 2004, pp. 1-18. doi:10.1016/j.ijpharm.2004.04.013

[15] J. Panyam and V. Labhasetwar, "Biodegradable Nanoparticles for Drug and Gene Delivery to Cells and Tissue," Advanced Drug Delivery Reviews, Vol. 55, No. 3, 2003, pp. 329-347. doi:10.1016/S0169-409X(02)00228-4

[16] C. Pinto Reis, R. J. Neufeld, A. N. J. Ribeiro and F. Veiga, "Nanoencapsulation I. Methods for Preparation of DrugLoaded Polymeric Nanoparticles," Nanomedicine: Nanotechnology, Biology, and Medicine, Vol. 2, No. 1, 2006, pp. 8-21. doi:10.1016/j.nano.2005.12.003

[17] M. P. Desai, V. Labhasetwar, E. Walter, R. J. Levy and G. L. Amidon, "The Mechanism of Uptake of Biodegradable Microparticles in Caco-2 Cells Is Size Dependent," Pharmaceutical Research, Vol. 14, No. 11, 1997, pp. 15681573. doi:10.1023/A:1012126301290

[18] Y. Avnir, K. Turjeman, D. Tulchinsky, A. Sigal and P. Kizelsztein, "Fabrication Principles and Their Contribution to the Superior in Vivo Therapeutic Efficacy of Nano-Liposomes Remote Loaded with Glucocorticoids," PLoS One, Vol. 6, No. 10, 2011, p. e25721. 


\section{doi:10.1371/journal.pone.0025721}

[19] M. Taglietti, C. N. Hawkins and J. Rao, "Novel Topical Drug Delivery Systems and Their Potential Use in Acne Vulgaris,” Skin Therapy Letter, Vol. 13, No. 5, 2008, pp. 6-8.

[20] W. Geldenhuys, T. Mbimba, T. Bui, K. Harrison and V. Sutariya, "Brain-Targeted Delivery of Paclitaxel Using Glutathione-Coated Nanoparticles for Brain Cancers," Journal of Drug Targeting, Vol. 19, No. 9, 2011, pp. 837845. doi:10.3109/1061186X.2011.589435

[21] O. Taratula, O. B. Garbuzenko, P. Kirkpatrick, I. Pandya and R. Savla, "Surface-Engineered Targeted PPI Dendrimer for Efficient Intracellular and Intratumoral siRNA Delivery," Journal of Controlled Release, Vol. 140, No. 3, 2009, pp. 284-293. doi:10.1016/j.jconrel.2009.06.019

[22] V. V. Mody, R. Siwale, A. Singh and H. R. Mody, "Introduction to Metallic Nanoparticles," Journal of Pharmacy and Bioallied Sciences, Vol. 2, No. 4, 2010, pp. 282-289. doi:10.4103/0975-7406.72127

[23] D. Brambilla, B. Le Droumaguet, J. Nicolas, S. H. Hashemi and L. P. Wu, "Nanotechnologies for Alzheimer's Disease: Diagnosis, Therapy, and Safety Issues,” Nanomedicine, Vol. 7, No. 5, 2011, pp. 521-540. doi:10.1016/j.nano.2011.03.008

[24] A. Beck, J. F. Haeuw, T. Wurch, L. Goetsch and C. Bailly, "The Next Generation of Antibody-Drug Conjugates Comes of Age," Discovery Medicine, Vol. 10, No. 53, 2010, pp. 329-339.

[25] A. M. Wu and P. D. Senter, "Arming Antibodies: Prospects and Challenges for Immunoconjugates," Nature Biotechnology, Vol. 23, No. 9, 2005, pp. 1137-1146. doi:10.1038/nbt1141

[26] A. L. Nelson, "Antibody Fragments: Hope and Hype," MAbs, Vol. 2, No. 1, 2010, pp. 77-83. doi:10.4161/mabs.2.1.10786

[27] J. M. Reichert, "Antibody-Based Therapeutics to Watch in 2011,” MAbs, Vol. 3, No. 1, 2011, pp. 76-99. doi:10.4161/mabs.3.1.13895

[28] J. C. Olivier, R. Huertas, H. J. Lee, F. Calon and W. M. Pardridge, "Synthesis of Pegylated Immunonanoparticles,” Pharmaceutical Research, Vol. 19, No. 8, 2002, pp. 1137-1143. doi:10.1023/A:1019842024814

[29] J. C. Olivier, "Drug Transport to Brain with Targeted Nanoparticles,” NeuroRx, Vol. 2, No. 1, 2005, pp. 108119. doi:10.1602/neurorx.2.1.108

[30] H. M. Blau and M. L. Springer, "Gene Therapy-A Novel Form of Drug Delivery,” The New England Journal of Medicine, Vol. 333, No. 18, 1995, pp. 1204-1207. doi:10.1056/NEJM199511023331808

[31] Y. Z. Chen, X. L. Yao, Y. Tabata, S. Nakagawa and J. Q. Gao, "Gene Carriers and Transfection Systems Used in the Recombination of Dendritic Cells for Effective Cancer Immunotherapy," Clinical and Developmental Immunology, Vol. 2010, 2010, Article ID 565643, 12 Pages. doi:10.1155/2010/565643

[32] H. Eliyahu, Y. Barenholz and A. J. Domb, "Polymers for DNA Delivery,” Molecules, Vol. 10, No. 1, 2005, pp. 34-

\section{4. doi:10.3390/10010034}

[33] B. Thaci, I. V. Ulasov, D. A. Wainwright and M. S. Lesniak, "The Challenge for Gene Therapy: Innate Immune Response to Adenoviruses," Oncotarget, Vol. 2, No. 3, 2011, pp. 113-121.

[34] M. G. Cusi, "Applications of Influenza Virosomes as a Delivery System,” Human Vaccine, Vol. 2, No. 1, 2006, pp. 1-7. doi:10.4161/hv.2.1.2494

[35] G. Fricker, T. Kromp, A. Wendel, A. Blume and J. Zirkel, "Phospholipids and Lipid-Based Formulations in Oral Drug Delivery,” Pharmaceutical Research, Vol. 27, No. 8, 2010, pp. 1469-1486. doi:10.1007/s11095-010-0130-x

[36] I. Gilead Sciences, “AmBisome,” 2011. http://www.ambisome.com/index2.php?section=about\&p age $=$ intro

[37] S. R. Schaffazick, A. R. Pohlmann, C. A. de Cordova, T. B. Creczynski-Pasa and S. S. Guterres, "Protective Properties of Melatonin-Loaded Nanoparticles against Lipid Peroxidation," International Journal of Pharmaceutics, Vol. 289, No. 1-2, 2005, pp. 209-213. doi:10.1016/j.ijpharm.2004.11.003

[38] M. S. Arayne, N. Sultana and F. Qureshi, "Review: Nanoparticles in Delivery of Cardiovascular Drugs," Pakistan Journal of Pharmaceutical Sciences, Vol. 20, No. 4, 2007, pp. 340-348.

[39] G. A. Castro, R. L. Orefice, J. M. Vilela, M. S. Andrade and L. A. Ferreira, "Development of a New Solid Lipid Nanoparticle Formulation Containing Retinoic Acid for Topical Treatment of Acne,” Journal of Microencapsulation, Vol. 24, No. 5, 2007, pp. 395-407. doi:10.1080/02652040701288519

[40] E. Esposito, E. Menegatti and R. Cortesi, "Ethosomes and Liposomes as Topical Vehicles for Azelaic Acid: A Preformulation Study,” Journal of Cosmetic Science, Vol. 55, No. 3, 2004, pp. 253-264.

[41] P. Karande and S. Mitragotri, "Enhancement of Transdermal Drug Delivery via Synergistic Action of Chemicals,” Biochimica et Biophysica Acta, Vol. 1788, No. 11, 2009, pp. 2362-2373. doi:10.1016/j.bbamem.2009.08.015

[42] R. D. Miclea, P. R. Varma, A. Peng and S. V. Balu-Iyer, "Development and Characterization of Lipidic Cochleate Containing Recombinant Factor VIII," Biochimica et Biophysica Acta, Vol. 1768, No. 11, 2007, pp. 2890-2898. doi:10.1016/j.bbamem.2007.08.001

[43] A. M. Sesana, R. Monti-Rocha, S. A. Vinhas, C. G. Morais and R. Dietze, "In Vitro Activity of Amphotericin B Cochleates against Leishmania Chagasi,” Memórias do Instituto Oswaldo Cruz, Vol. 106, No. 2, 2011, pp. 251253. doi:10.1590/S0074-02762011000200022

[44] O. Perez, G. Bracho, M. Lastre, N. Mora and J. del Campo, "Novel Adjuvant Based on a ProteoliposomeDerived Cochleate Structure Containing Native Lipopolysaccharide as a Pathogen-Associated Molecular Pattern," Immunology \& Cell Biology, Vol. 82, No. 6, 2004, pp. 603-610. doi:10.1111/j.1440-1711.2004.01293.x

[45] Z. Yang, X. Peng, Y. Tan, M. Chen and X. Zhu, "Optimization of the Preparation Process for an Oral Phytan- 
triol-Based Amphotericin B Cubosomes," Journal of Nanomaterials, Vol. Vol. 2011, No. 2011, p. 10.

[46] D. Bei, T. Zhang, J. B. Murowchick and B. B. Youan, "Formulation of Dacarbazine-Loaded Cubosomes. Part III. Physicochemical Characterization," AAPS PharmSciTech, Vol. 11, No. 3, 2010, pp. 1243-1249. doi:10.1208/s12249-010-9496-7

[47] H. Chung, J. Kim, J. Y. Um, I. C. Kwon and S. Y. Jeong, "Self-Assembled 'Nanocubicle' as a Carrier for Peroral Insulin Delivery,” Diabetologia, Vol. 45, No. 3, 2002, pp. 448-451. doi:10.1007/s00125-001-0751-Z

[48] J. Manosroi, M. G. Apriyani, K. Foe and A. Manosroi, "Enhancement of the Release of Azelaic Acid through the Synthetic Membranes by Inclusion Complex Formation with Hydroxypropyl-beta-cyclodextrin,” International Journal of Pharmaceutics, Vol. 293, No. 1-2, 2005, pp. 235-240. doi:10.1016/j.ijpharm.2005.01.009

[49] R. R. Arvizo, O. R. Miranda, D. F. Moyano, C. A. Walden and K. Giri, "Modulating Pharmacokinetics, Tumor Uptake and Biodistribution by Engineered Nanoparticles,” PLoS One, Vol. 6, No. 9, 2011, p. e24374. doi:10.1371/journal.pone.0024374

[50] J. L. Arias, "Novel Strategies to Improve the Anticancer Action of 5-Fluorouracil by Using Drug Delivery Systems,” Molecules, Vol. 13, No. 10, 2008, pp. 2340-2369. doi:10.3390/molecules 13102340

[51] S. K. Jain and N. K. Jain, "Multiparticulate Carriers for Sun-Screening Agents," International Journal of Cosmetic Science, Vol. 32, No. 2, 2010, pp. 89-98. doi:10.1111/j.1468-2494.2010.00547.x

[52] T. Fauce, "Exploring the Safety of Nanoparticles in Australian Sunscreens," International Journal of Biomedical Nanoscience and Nanotechnology, Vol. 1, No. 1, 2010, pp. 87-94. doi:10.1504/IJBNN.2010.034127

[53] P. C. Chen, S. C. Mwakwari and A. K. Oyelere, "Gold Nanoparticles: From Nanomedicine to Nanosensing," Nanotechnology, Science and Applications, Vol. 1, No. 2008, pp. 45-66.

[54] L. M. Kaminskas, B. J. Boyd and C. J. Porter, "Dendrimer Pharmacokinetics: The Effect of Size, Structure and Surface Characteristics on ADME Properties," Nanomedicine, Vol. 6, No. 6, 2011, pp. 1063-1084. doi:10.2217/nnm.11.67

[55] J. F. Kukowska-Latallo, K. A. Candido, Z. Cao, S. S. Nigavekar and I. J. Majoros, "Nanoparticle Targeting of Anticancer Drug Improves Therapeutic Response in Animal Model of Human Epithelial Cancer," Cancer Research, Vol. 65, No. 12, 2005, pp. 5317-5324. doi:10.1158/0008-5472.CAN-04-3921

[56] A. R. Menjoge, R. M. Kannan and D. A. Tomalia, "Dendrimer-Based Drug and Imaging Conjugates: Design Considerations for Nanomedical Applications," Drug Discovery Today, Vol. 15, No. 5-6, 2010, pp. 171-185. doi:10.1016/j.drudis.2010.01.009

[57] S. H. Medina, V. Tekumalla, M. V. Chevliakov, D. S. Shewach and W. D. Ensminger, "N-AcetylgalactosamineFunctionalized Dendrimers as Hepatic Cancer Cell-Tar- geted Carriers,” Biomaterials, Vol. 32, No. 17, 2011, pp. 4118- 4129. doi:10.1016/j.biomaterials.2010.11.068

[58] Y.-B. Lim, T. Kim, J. W. Lee, S.-M. Kim and H.-J. Kim, "Self-Assembled Ternary Complex of Cationic Dendrimer, Cucurbituril, and DNA: Noncovalent Strategy in Developing a Gene Delivery Carrier,” Bioconjugate Chemistry, Vol. 13, No. 6, 2002, pp. 1181-1185. doi:10.1021/bc025581r

[59] A. J. Velazquez, M. A. Carnahan, J. Kristinsson, S. Stinnett and M. W. Grinstaff, "New Dendritic Adhesives for Sutureless Ophthalmic Surgical Procedures: In Vitro Studies of Corneal Laceration Repair," Archives of Ophthalmology, Vol. 122, No. 6, 2004, pp. 867-870. doi:10.1001/archopht.122.6.867

[60] A. K. Patri, A. Myc, J. Beals, T. P. Thomas and N. H. Bander, "Synthesis and in Vitro Testing of J591 Antibody-Dendrimer Conjugates for Targeted Prostate Cancer Therapy,” Bioconjugate Chemistry, Vol. 15, No. 6, 2004, pp. 1174-1181. doi:10.1021/bc0499127

[61] K. Sugisaki, T. Usui, N. Nishiyama, W. D. Jang and Y. Yanagi, "Photodynamic Therapy for Corneal Neovascularization Using Polymeric Micelles Encapsulating Dendrimer Porphyrins," Investigative Ophthalmology \& Visual Science, Vol. 49, No. 3, 2008, pp. 894-899. doi:10.1167/iovs.07-0389

[62] K. M. Kitchens, A. B. Foraker, R. B. Kolhatkar, P. W. Swaan and H. Ghandehari, "Endocytosis and Interaction of Poly(amidoamine) Dendrimers with Caco-2 Cells," Pharmaceutical Research, Vol. 24, No. 11, 2007, pp. 2138-2145. doi:10.1007/s11095-007-9415-0

[63] P. Singh, "Dendrimers and Their Applications in Immunoassays and Clinical Diagnostics," Biotechnology and Applied Biochemistry, Vol. 48, No. Pt 1, 2007, pp. 1-9.

[64] QIAGEN, “SuperFect Transfection Reagent," http://www.qiagen.com/products/transfection/transfection reagents/superfecttransfectionreagent.aspx\#Tabs=t0

[65] STARPHARMA, “Transfection Reagents,” http://www.starpharma.com/life_sciences/transfection_re agents\#article

[66] STARPHARMA, "Coatings, Inks and Adhesives," http://www.starpharma.com/wider_uses/coatings_inks_a nd_adhesives\#article

[67] DendriticNanotechnologiesInc., 2011. http://www.dnanotech.com/aboutus.asp

[68] C. F. Price, D. Tyssen, S. Sonza, A. Davie and S. Evans, "SPL7013 Gel (VivaGel(R)) Retains Potent HIV-1 and HSV-2 Inhibitory Activity Following Vaginal Administration in Humans," PLoS One, Vol. 6, No. 9, 2011, p. e24095. doi:10.1371/journal.pone.0024095

[69] C. Pinto Reis, R. J. Neufeld, A. N. J. Ribeiro and F. Veiga, "Nanoencapsulation II. Biomedical Applications and Current Status of Peptide and Protein Nanoparticulate Delivery Systems," Nanomedicine: Nanotechnology, Biology and Medicine, Vol. 2, No. 2, 2006, pp. 53-65. doi:10.1016/j.nano.2006.04.009

[70] R. Alvarez-Roman, A. Naik, Y. N. Kalia, R. H. Guy and H. Fessi, "Enhancement of Topical Delivery from Biode- 
gradable Nanoparticles,” Pharmaceutical Research, Vol. 21, No. 10, 2004, pp. 1818-1825. doi:10.1023/B:PHAM.0000045235.86197.ef

[71] N. Nafee, M. Schneider, U. F. Schaefer and C. M. Lehr, "Relevance of the Colloidal Stability of Chitosan/PLGA Nanoparticles on Their Cytotoxicity Profile," International Journal of Pharmaceutics, Vol. 381, No. 2, 2009, pp. 130-139. doi:10.1016/j.ijpharm.2009.04.049

[72] A. C. B. P. Reis, "Encapsulação de Fármacos Peptídicos Pelo Método de Emulsificação/Gelificação Interna,” Ph.D. Thesis, Faculdade Farmácia Universidade de Coimbra, 2007.

[73] T. Y. Lim, C. K. Poh and W. Wang, "Poly(lactic-coglycolic acid) as a Controlled Release Delivery Device," Journal of Materials Science: Materials in Medicine, Vol. 20, No. 8, 2009, pp. 1669-1675. doi:10.1007/s10856-009-3727-z

[74] J. K. Park, J. Yeom, E. J. Oh, M. Reddy and J. Y. Kim, "Guided Bone Regeneration by Poly(lactic-co-glycolic acid) Grafted Hyaluronic Acid Bi-Layer Films for Periodontal Barrier Applications,” Acta Biomaterialia, Vol. 5, No. 9, 2009, pp. 3394-3403.

doi:10.1016/j.actbio.2009.05.019

[75] N. Vij, T. Min, R. Marasigan, C. N. Belcher and S. Mazur, "Development of PEGylated PLGA Nanoparticle for Controlled and Sustained Drug Delivery in Cystic Fibrosis,” Journal of Nanobiotechnology, Vol. 8, 2010, p. 22. doi:10.1186/1477-3155-8-22

[76] N. Csaba, A. Sanchez and M. J. Alonso, "PLGA: Poloxamer and PLGA: Poloxamine Blend Nanostructures as Carriers for Nasal Gene Delivery,” Journal of Controlled Release, Vol. 113, No. 2, 2006, pp. 164-172. doi:10.1016/j.jconrel.2006.03.017

[77] S. R. Little, D. M. Lynn, Q. Ge, D. G. Anderson and S. V. Puram, "Poly-Beta Amino Ester-Containing Microparticles Enhance the Activity of Nonviral Genetic Vaccines," Proceedings of the National Academy of Sciences, Vol. 101, No. 26, 2004, pp. 9534-9539. doi:10.1073/pnas.0403549101

[78] D. Shenoy, S. Little, R. Langer and M. Amiji, "Poly(ethylene oxide)-Modified Poly(beta-amino ester) Nanoparticles as a pH-Sensitive System for Tumor-Targeted Delivery of Hydrophobic Drugs. 1. In Vitro Evaluations," Molecular Pharmaceutics, Vol. 2, No. 5, 2005, pp. 357-366. doi:10.1021/mp0500420

[79] T. M. Allen, "Ligand-Targeted Therapeutics in Anticancer Therapy," Nature Reviews Cancer, Vol. 2, No. 10, 2002, pp. 750-763. doi:10.1038/nrc903

[80] R. Gabathuler, "Development of New Peptide Vectors for the Transport of Therapeutic across the Blood-Brain Barrier," Therapeutic Delivery, Vol. 1, No. 4, 2010, pp. 571-586. doi:10.4155/tde.10.35

[81] M. F. Bennewitz and W. M. Saltzman, "Nanotechnology for Delivery of Drugs to the Brain for Epilepsy," Neurotherapeutics, Vol. 6, No. 2, 2009, pp. 323-336. doi:10.1016/j.nurt.2009.01.018

[82] J. Park, P. M. Fong, J. Lu, K. S. Russell and C. J. Booth,
"PEGylated PLGA Nanoparticles for the Improved Delivery of Doxorubicin," Nanomedicine, Vol. 5, No. 4, 2009, pp. 410-418. doi:10.1016/j.nano.2009.02.002

[83] P. J. Gaillard, “Crossing Barriers from Blood-to-Brain and Academia-to-Industry," Therapeutic Delivery, Vol. 1, No. 4, 2010, pp. 495-500. doi:10.4155/tde.10.43

[84] M. Habgood and J. Ek, "Delivering Drugs into the Brain: Barriers and Possibilities," Therapeutic Delivery, Vol. 1, No. 4, 2010, pp. 483-488. doi:10.4155/tde.10.58

[85] E. Garcia-Garcia, K. Andrieux, S. Gil and P. Couvreur, "Colloidal Carriers and Blood-Brain Barrier (BBB) Translocation: A Way to Deliver Drugs to the Brain?” International Journal of Pharmaceutics, Vol. 298, No. 2, 2005, pp. 274-292. doi:10.1016/j.ijpharm.2005.03.031

[86] D. Chen, W. Liu, Y. Shen, H. Mu and Y. Zhang, "Effects of a Novel pH-Sensitive Liposome with Cleavable Esterase-Catalyzed and pH-Responsive Double Smart mPEG Lipid Derivative on ABC Phenomenon," International Journal of Nanomedicine, Vol. 6, 2011, pp. 20532061.

[87] D. Shenoy, S. Little, R. Langer and M. Amiji, "Poly(ethylene oxide)-Modified Poly(beta-amino ester) Nanoparticles as a pH-Sensitive System for Tumor-Targeted Delivery of Hydrophobic Drugs: Part 2. In Vivo Distribution and Tumor Localization Studies," Pharmaceutical Research, Vol. 22, No. 12, 2005, pp. 2107-2114. doi:10.1007/s11095-005-8343-0

[88] B. C. Tang, M. Dawson, S. K. Lai, Y. Y. Wang and J. S. Suk, "Biodegradable Polymer Nanoparticles That Rapidly Penetrate the Human Mucus Barrier," Proceedings of the National Academy of Sciences, Vol. 106, No. 46, 2009, pp. 19268-19273. doi:10.1073/pnas.0905998106

[89] R. Yang, W. S. Shim, F. D. Cui, G. Cheng and X. Han, "Enhanced Electrostatic Interaction between ChitosanModified PLGA Nanoparticle and Tumor,” International Journal of Pharmaceutics, Vol. 371, No. 1-2, 2009, pp. 142-147. doi:10.1016/j.ijpharm.2008.12.007

[90] T. Dos Santos, J. Varela, I. Lynch, A. Salvati and K. A. Dawson, "Effects of Transport Inhibitors on the Cellular Uptake of Carboxylated Polystyrene Nanoparticles in Different Cell Lines,” PLoS One, Vol. 6, No. 9, 2011, p. e24438. doi:10.1371/journal.pone.0024438

[91] A. S. Hasan, M. Socha, A. Lamprecht, F. E. Ghazouani and A. Sapin, "Effect of the Microencapsulation of Nanoparticles on the Reduction of Burst Release," International Journal of Pharmaceutics, Vol. 344, No. 1-2, 2007, pp. 53-61. doi:10.1016/j.ijpharm.2007.05.066

[92] S. S. Feng, G. Ruan and Q. T. Li, "Fabrication and Characterizations of a Novel Drug Delivery Device Liposomes-in-Microsphere (LIM),” Biomaterials, Vol. 25, No. 21, 2004, pp. 5181-5189. doi:10.1016/j.biomaterials.2003.12.013

[93] R. K. Das, N. Kasoju and U. Bora, "Encapsulation of Curcumin in Alginate-Chitosan-Pluronic Composite Nanoparticles for Delivery to Cancer Cells," Nanomedicine, Vol. 6, No. 1, 2010, pp. 153-160. doi:10.1016/j.nano.2009.05.009 
[94] A. S. Hassan, "Prolonged Release Microparticles Able to Reduce the Initial Burst Effect,” Ph.D. Thesis, Universite Henri Poincare, Nancy 1, 2008.

[95] T. Hammady, A. El-Gindy, E. Lejmi, R. S. Dhanikula and P. Moreau, "Characteristics and Properties of Nanospheres Co-Loaded with Lipophilic and Hydrophilic Drug Models," International Journal of Pharmaceutics, Vol. 369, No. 1-2, 2009, pp. 185-195. doi:10.1016/j.ijpharm.2008.10.034

[96] A. Budhian, S. J. Siegel and K. I. Winey, "Controlling the in Vitro Release Profiles for a System of HaloperidolLoaded PLGA Nanoparticles," International Journal of Pharmaceutics, Vol. 346, No. 1-2, 2008, pp. 151-159. doi:10.1016/j.ijpharm.2007.06.011

[97] R. M. Mainardes and R. C. Evangelista, "PLGA Nanoparticles Containing Praziquantel: Effect of Formulation Variables on Size Distribution,” International Journal of Pharmaceutics, Vol. 290, No. 1-2, 2005, pp. 137144. doi:10.1016/j.ijpharm.2004.11.027

[98] X. Song, Y. Zhao, W. Wu, Y. Bi and Z. Cai, "PLGA Nanoparticles Simultaneously Loaded with Vincristine Sulfate and Verapamil Hydrochloride: Systematic Study of Particle Size and Drug Entrapment Efficiency,” International Journal of Pharmaceutics, Vol. 350, No. 1-2, 2008, pp. 320-329. doi:10.1016/j.ijpharm.2007.08.034

[99] W. Ke, Y. Zhao, R. Huang, C. Jiang and Y. Pei, "Enhanced Oral Bioavailability of Doxorubicin in a Dendrimer Drug Delivery System,” Journal of Pharmaceutical Sciences, Vol. 97, No. 6, 2008, pp. 2208-2216. doi:10.1002/jps.21155

[100] W. A. Banks and A. J. Kastin, "Aluminum Alters the Permeability of the Blood-Brain Barrier to Some NonPeptides," Neuropharmacology, Vol. 24, No. 5, 1985, pp. 407-412. doi:10.1016/0028-3908(85)90025-5

[101] P. Vlieghe and M. Khrestchatisky, "Peptide-Based Vectors for Blood-Brain Barrier Targeting and Delivery of Drugs to the Central Nervous System," Therapeutic Delivery, Vol. 1, No. 4, 2010, pp. 489-494. doi:10.4155/tde.10.44

[102] B. Wilson, "Brain Targeting PBCA Nanoparticles and the Blood-Brain Barrier,” Nanomedicine, Vol. 4, No. 5, 2009, pp. 499-502. doi:10.2217/nnm.09.29

[103] V. Mangas-Sanjuan, M. González-Alvarez, I. GonzalezAlvarez and M. Bermejo, "Drug Penetration across the Blood-Brain Barrier: An Overview," Therapeutic Delivery, Vol. 1, No. 4, 2010, pp. 535-562.

doi:10.4155/tde.10.37

[104] A. Misra, S. Ganesh, A. Shahiwala and S. P. Shah, "Drug Delivery to the Central Nervous System: A Review," Journal of Pharmaceutical Sciences, Vol. 6, No. 2, 2003, pp. 252-273.

[105] S. J. Gray, K. T. Woodard and R. J. Samulski, "Viral Vectors and Delivery Strategies for CNS Gene Therapy," Therapeutic Delivery, Vol. 1, No. 4, 2010, pp. 517-534. doi:10.4155/tde.10.50

[106] R. N. Alyautdin, V. E. Petrov, K. Langer, A. Berthold and D. A. Kharkevich, "Delivery of Loperamide across the
Blood-Brain Barrier with Polysorbate 80-Coated Polybutylcyanoacrylate Nanoparticles," Pharmaceutical Research, Vol. 14, No. 3, 1997, pp. 325-328. doi:10.1023/A:1012098005098

[107] J. Kreuter, D. Shamenkov, V. Petrov, P. Ramge and K. Cychutek, "Apolipoprotein-Mediated Transport of Nanoparticle-Bound Drugs across the Blood-Brain Barrier," Journal of Drug Targeting, Vol. 10, No. 4, 2002, pp. 317 325. doi:10.1080/10611860290031877

[108] J. Kreuter and S. Gelperina, "Use of Nanoparticles for Cerebral Cancer,” Tumori, Vol. 94, No. 2008, pp. 270276.

[109] F. C. Thomas, K. Taskar, V. Rudraraju, S. Goda and H. R. Thorsheim, "Uptake of ANG1005, a Novel Paclitaxel Derivative, through the Blood-Brain Barrier into Brain and Experimental Brain Metastases of Breast Cancer," Pharmaceutical Research, Vol. 26, No. 11, 2009, pp. 2486-2494. doi:10.1007/s11095-009-9964-5

[110] S. Bhaskar, F. Tian, T. Stoeger, W. Kreyling and J. M. de la Fuente, "Multifunctional Nanocarriers for Diagnostics, Drug Delivery and Targeted Treatment across BloodBrain Barrier: Perspectives on Tracking and Neuroimaging," Particle and Fibre Toxicology, Vol. 7, 2010, p. 3. doi:10.1186/1743-8977-7-3

[111] H. Xin, X. Jiang, J. Gu, X. Sha and L. Chen, “AngiopepConjugated Poly(ethylene glycol)-co-poly(epsilon-caprolactone) Nanoparticles as Dual-Targeting Drug Delivery System for Brain Glioma,” Biomaterials, Vol. 32, No. 18, 2011, pp. 4293-4305. doi:10.1016/j.biomaterials.2011.02.044

[112] EMA, “Glutathione-Pegylated Liposomal Doxorubicin Hydrochloride for the Treatment of Glioma,” 2010. http://www.ema.europa.eu/docs/en_GB/document_library /Orphan_designation/2010/10/WC500097951.pdf

[113] H.-L. Zhang, S.-H. Wu, Y. Tao, L.-Q. Zang and Z.-Q. Su, "Preparation and Characterization of Water-Soluble Chitosan Nanoparticles as Protein Delivery System,” Journal of Nanomaterials, Vol. 2010, 2010, Article ID 898910, 5 Pages.

[114] M. Garinot, V. Fievez, V. Pourcelle, F. Stoffelbach and A. des Rieux, "PEGylated PLGA-Based Nanoparticles Targeting M Cells for Oral Vaccination,” Journal of Controlled Release, Vol. 120, No. 3, 2007, pp. 195-204. doi:10.1016/j.jconrel.2007.04.021

[115] V. Fievez, L. Plapied, A. des Rieux, V. Pourcelle and H. Freichels, "Targeting Nanoparticles to M Cells with NonPeptidic Ligands for Oral Vaccination,” European Journal of Pharmaceutics and Biopharmaceutics, Vol. 73, No. 1, 2009, pp. 16-24. doi:10.1016/j.ejpb.2009.04.009

[116] Y. Pan, Y. J. Li, H. Y. Zhao, J. M. Zheng and H. Xu, "Bioadhesive Polysaccharide in Protein Delivery System: Chitosan Nanoparticles Improve the Intestinal Absorption of Insulin in Vivo,” International Journal of Pharmaceutics, Vol. 249, No. 1-2, 2002, pp. 139-147. doi:10.1016/S0378-5173(02)00486-6

[117] W. S. Shalaby, "Development of Oral Vaccines to Stimulate Mucosal and Systemic Immunity: Barriers and Novel 
Strategies," Clinical Immunology and Immunopathology, Vol. 74, No. 2, 1995, pp. 127-134. doi:10.1006/clin.1995.1019

[118] C. O. Tacket, M. B. Sztein, S. S. Wasserman, G. Losonsky and K. L. Kotloff, "Phase 2 Clinical Trial of Attenuated Salmonella Enterica Serovar Typhi Oral Live Vector Vaccine CVD 908-htrA in U.S. Volunteers," Infection and Immunity, Vol. 68, No. 3, 2000, pp. 1196-1201. doi:10.1128/IAI.68.3.1196-1201.2000

[119] G. P. Li, Z. G. Liu, B. Liao and N. S. Zhong, "Induction of Th1-Type Immune Response by Chitosan Nanoparticles Containing Plasmid DNA Encoding House Dust Mite Allergen Der p 2 for Oral Vaccination in Mice," Cellular \& Molecular Immunology, Vol. 6, No. 1, 2009, pp. 45-50. doi:10.1038/cmi.2009.6

[120] I. S. Kim, S. K. Lee, Y. M. Park, Y. B. Lee and S. C. Shin, "Physicochemical Characterization of Poly(L-lactic acid) and Poly(D,L-lactide-co-glycolide) Nanoparticles with Polyethylenimine as Gene Delivery Carrier," International Journal of Pharmaceutics, Vol. 298, No. 1, 2005, pp. 255-262. doi:10.1016/j.ijpharm.2005.04.017

[121] ANGELINI, "EPAXAL ${ }^{\circledR}$ - Vaccine for Active Immunisation against Hepatitis A,” 2011. http://www.angelini.it/public/schedepharma/epaxal.htm

[122] PEVION, "Virosomes Are the Only VLP Assembled in Vitro, Not by Host Cell,"

http://www.pevion.com/index.php?page=723

[123] M. R. Kumar, U. Bakowsky and C. M. Lehr, "Preparation and Characterization of Cationic PLGA Nanospheres as DNA Carriers,” Biomaterials, Vol. 25, No. 10, 2004, pp. 1771-1777. doi:10.1016/j.biomaterials.2003.08.069

[124] Y. Yue, F. Jin, R. Deng, J. Cai and Z. Dai, "Revisit Complexation between DNA and Polyethylenimine-Effect of Length of Free Polycationic Chains on Gene Transfection," Journal of Controlled Release, Vol. 152, No. 1, 2011, pp. 143-151. doi:10.1016/j.jconrel.2011.03.020

[125] J. L. Italia, A. Sharp, K. C. Carter, P. Warn and M. N. V. R. Kumar, "Peroral Amphotericin B Polymer Nanoparticles Lead to Comparable or Superior in Vivo Antifungal Activity to That of Intravenous Ambisome ${ }^{\circledR}$ or Fungizone $^{\mathrm{TM}}$," PLoS One, Vol. 6, No. 10, 2011, p. 8. doi:10.1371/journal.pone.0025744

[126] R. Rupp, S. L. Rosenthal and L. R. Stanberry, "VivaGel (SPL7013 Gel): A Candidate Dendrimer-Microbicide for the Prevention of HIV and HSV Infection,” International Journal of Nanomedicine, Vol. 2, No. 4, 2007, pp. 561-566.
[127] C. S. Maia, W. Mehnert and M. Schäfer-Korting, "Solid lipid Nanoparticles as Drug Carriers for Topical Glucocorticoids," International Journal of Pharmaceutics, Vol. 196, No. 2, 2000, pp. 165-167. doi:10.1016/S0378-5173(99)00413-5

[128] H. Chen, X. Chang, D. Du, W. Liu and J. Liu, "Podophyllotoxin-Loaded Solid Lipid Nanoparticles for Epidermal Targeting," Journal of Controlled Release, Vol. 110, No. 2, 2006, pp. 296-306. doi:10.1016/j.jconrel.2005.09.052

[129] M. Rother, E. J. Seidel, P. M. Clarkson, S. Mazgareanu and U. Vierl, "Efficacy of Epicutaneous Diractin (ketoprofen in Transfersome gel) for the Treatment of Pain Related to Eccentric Muscle Contractions," Journal of Drug Design, Development and Therapy, Vol. 3, 2009, pp. 143-149.

[130] A. Rolland, N. Wagner, A. Chatelus, B. Shroot and H. Schaefer, "Site-Specific Drug Delivery to Pilosebaceous Structures Using Polymeric Microspheres,” Pharmaceutical Research, Vol. 10, No. 12, 1993, pp. 1738-1744. doi:10.1023/A:1018922114398

[131] B. Mahe, A. Vogt, C. Liard, D. Duffy and V. Abadie, "Nanoparticle-Based Targeting of Vaccine Compounds to Skin Antigen-Presenting Cells by Hair Follicles and Their Transport in Mice,” Journal of Investigative Dermatology, Vol. 129, No. 5, 2009, pp. 1156-1164. doi:10.1038/jid.2008.356

[132] A. Vogt, B. Combadiere, S. Hadam, K. M. Stieler and J. Lademann, " 40 nm, but not 750 or 1500 nm, Nanoparticles Enter Epidermal CD1a+ Cells after Transcutaneous Application on Human Skin," Journal of Investigative Dermatology, Vol. 126, No. 6, 2006, pp. 1316-1322. doi:10.1038/sj.jid.5700226

[133] F. F. Larese, F. D'Agostin, M. Crosera, G. Adami and N. Renzi, "Human Skin Penetration of Silver Nanoparticles through Intact and Damaged Skin,” Toxicology, Vol. 255, No. 1-2, 2009, pp. 33-37. doi:10.1016/j.tox.2008.09.025

[134] H. Maeda, J. Wu, T. Sawa, Y. Matsumura and K. Hori, "Tumor Vascular Permeability and the EPR Effect in Macromolecular Therapeutics: A Review," Journal of Controlled Release, Vol. 65, No. 1-2, 2000, pp. 271-284. doi:10.1016/S0168-3659(99)00248-5

[135] H. Sarin, "Recent Progress towards Development of Effective Systemic Chemotherapy for the Treatment of Malignant Brain Tumors," Journal of Translational Medicine, Vol. 7, 2009, p. 77. doi:10.1186/1479-5876-7-77 